\title{
The contribution of the associative parietal cortex and hippocampus to spatial processing in rodents
}

\author{
ETIENNE SAVE and BRUNO POUCET \\ Center for Research in Cognitive Neuroscience, Marseille, France \\ NIGEL FOREMAN \\ University of Leicester, Leicester, England \\ and \\ CATHERINE THINUS-BLANC \\ Center for Research in Cognitive Neuroscience, Marseille, France
}

\begin{abstract}
A growing volume of data supports the notion that the associative parietal cortex (APC) in rodents plays an important role in the processing of spatial information. The present paper reviews the literature and available data, emphasizing the respective contribution of the APC and the hippocampus to spatial processing. It is proposed that the APC has a function of interfacing between the egocentric and allocentric coding of space. According to this view, the APC would associate visuospatial and internal movement-related information and thus would mediate the integration of multiple egocentric frames of reference into allocentric spatial representations. The allocentric coding of space would be completed and implemented in the hippocampal formation.
\end{abstract}

Although the current focus on the role of the cortex in learning and memory in rats can be traced back to the first half of the century (Lashley, 1929), it is only recently that a systematic study of the associative parietal cortex (APC) has been undertaken. One historical reason is that, because the phylogenetic extension of associative cortices in the brain has traditionally been linked to the development of intellectual faculties in hominids, such lower species as the rat have been more or less denied possession of such areas. Another reason is that the effects of cortical injuries upon the performance of learned tasks in the rat have long been the subject of controversy regarding the putative role of this structure in memory processes (Meyer, 1984).

Early research into the function of the APC in rodents was in part inspired by studies of the syndrome produced by damage to the (arguably homologous) parietal cortical regions in monkeys and in humans. Studies of monkeys suggested a prominent parietal role in spatial functions (Lynch, 1980), particularly reaching (Faugier-Grimaud, Frenois, \& Stein, 1978). Since Balint (1909, cited by Hyvärinen, 1982), patients with bilateral or unilateral posterior parietal lesions have been known to suffer from a constellation of symptoms that have in common their being related to the processing of space and the spatial direction of attention, including navigational disorientation. It was initially tempting to compare the effects of lesions of the APC with those observed after parietal damage in pri-

Correspondence should be addressed to $\mathrm{E}$. Save, Centre de Recherche en Neurosciences Cognitives, CNRS, 31 chemin Joseph-Aiguier, 13402 Marseille Cedex 20, France (e-mail: save@lnf.cnrs-mrs.fr). mates and humans by testing rats in mazes to examine spatial learning (Boyd \& Thomas, 1977; Davey, Rose, Dell, \& Love, 1988; Kolb \& Whishaw, 1983; Thomas \& Weir, 1975). Nevertheless, with the progressive elaboration of more comprehensive models of animal spatial cognition, the scope of APC studies in rodents appears to have changed somewhat, in line with developments in understanding the spatial functions of other brain structures. In the rat, it is now widely accepted that the hippocampal formation plays a fundamental role in the formation of allocentric spatial representations (O'Keefe \& Nadel, 1978). The fact that other brain areas like the APC may be involved in the processing of spatial information raises the essential issue of the functional interactions, interdependence, and division of labor among these structures. We selectively reviewed the lesion and electrophysiological literature regarding the role of the APC in various aspects of spatial processing and, in particular, spatial navigation. This led us to propose that the APC associates visuospatial and movement information, which allows it to provide an interface between the egocentric and the allocentric coding of space.

\section{THE ASSOCIATIVE PARIETAL CORTEX IN RODENTS: A SPECIFIC BRAIN REGION?}

Krieg (1946) was the first to assert the neuroanatomical specificity of the APC. Relying mainly on an examination of the cytoarchitecture, Krieg described a "region [that] should be the triangular zone between the three main sensory areas" (p. 245) and named it area 7. This finding has been confirmed subsequently (Kolb \& Walkey, 1987). In addition, recent studies using fluorescent retrograde ax- 
onal tracers have revealed a cortico-cortical connectivity consistent with the associative area hypothesis (Kolb \& Walkey, 1987; Reep, Chandler, King, \& Corwin, 1994). Schematically, the APC receives projections from the visual (Oc2L, Oc2M), somatosensory (Par 1), temporal (Te1, Te2), frontal and prefrontal (Fr2, LO, VLO), cingulate $(\mathrm{Cg})$, and retrosplenial (RSA and RSG) cortices (Kolb, 1990; Reep et al., 1994). Interestingly, Reep and his colleagues have shown that the cortical connections of APC are different from those of the neighboring secondary visual, hindlimb, and retrosplenial areas, leading to refinement in the delineation of APC boundaries on the basis of cortico-cortical connections.

The boundaries of the APC have also been defined with respect to its connections with the thalamus. Several authors using the retrograde degeneration method identified specific thalamic projections from the latero-posterior nucleus, part of the laterodorsal nucleus, and the posterior nucleus (Lashley, 1941; McDaniel, McDaniel, \& Thomas, 1978; Reep et al., 1994). This organization, roughly similar to parietal connectivity in the primate brain (Hyvärinen, 1982), strongly suggests that one function of area 7 is to perform multisensory associations.

\section{EFFECTS OF LESIONS ON SPATIAL CODING: A REVIEW}

\section{Forms of Spatial Coding}

The encoding of spatial information can rely on two distinct systems, namely the egocentric and the allocentric coding systems. In egocentric coding, spatial relationships, as they are extracted from sensory inputs, are referred to the body of the organism. They strictly depend on the current position of the animal. Egocentric coding enables animals to perform route-based navigation (as outlined by O'Keefe and Nadel, 1978, in their discussion of taxon strategies). In fact, this system encompasses various spatial subsystems that are presumably focused on different body frames of reference (e.g., eye, head, trunk, etc.) and on different sorts of information (Nadel, 1991). One or more of these subsystems must utilize internally generated (kinesthetic) information, enabling the animal to monitor its position on an ongoing basis, according to the speed/duration and direction of successive movements ("path integration"). Another system may deal with the use of visual information when the animal has to approach a noticeable landmark.

In contrast, the allocentric system codes the relationships between remote landmarks in the environment and between places. It enables the animal to perform place navigation independently of its position and location given that landmark information is available. When an animal navigates through space, sensory inputs are registered initially according to body-centered frames of reference. Similarly, appropriate overt orienting behavior requires that motor outputs also be coded in egocentric formats compatible with action (in terms of left, right, straight ahead, etc.). Thus, in line with earlier commen- taries (Thinus-Blanc, Save, Buhot, \& Poucet, 1991), we assume that the formation of an allocentric representation of the environment (in which places and landmarks are represented irrespective of a specific point of view or trajectory) requires the integration of multiple egocentric frames of reference. From this it follows that there would need to be a mechanism allowing for the two-way conversion of spatial information between the egocentric and allocentric frames of reference (Benhamou, Bovet, \& Poucet, 1995; Poucet \& Benhamou, 1997; Thinus-Blanc et al., 1991). In the last 20 years, many behavioral tasks have been developed to assess these various aspects of the processing of spatial information in rodents. These tasks have been used to study not only the cognitive processes at work during navigation but also the role of several brain regions in these processes.

In the next two sections, we briefly review some of the effects of APC lesions in spatial tasks and compare them with the effects of hippocampal lesions in the same tasks whenever possible.

\section{Effects of Lesions on Allocentric Coding}

Numerous studies have shown that hippocampal damage produces severe and lasting deficits in allocentric tasks- that is, when animals have to learn to navigate toward a goal whose location can be inferred using the relational properties of distal visual cues (e.g., Morris water task, Morris, Garrud, Rawlins, \& O'Keefe, 1982). Together with other evidence, this demonstrates that the hippocampus is critically involved in the formation of an allocentric representation of the spatial layout. In contrast, it has been shown that egocentric spatial coding does not seem to depend on the integrity of the hippocampus. For instance, rats with hippocampal lesions are able to swim to a visible or cued platform in the water maze (McDonald \& White, 1994; Packard \& McGaugh, 1992; Whishaw \& Jarrard, 1996), nor are they impaired in right/left discrimination learning (Kesner, Bolland, \& Dakis, 1993; Thompson, 1979). Hippocampal-lesioned rats can also learn to navigate to a hidden platform from a single starting point - that is, by following an egocentrically defined, constant path (Eichenbaum, Stewart, \& Morris, 1990).

It is potentially useful to consider possible roles for APC within this conceptual framework in terms of allocentric and egocentric processes. Surprisingly, relatively few studies have tested the impact of APC lesions on allocentric place learning. The magnitude of deficits seems to depend on the extent of the lesion. For example, whereas rats with parietal lesions encroaching both the somatosensory parietal and temporal cortices demonstrated a severe impairment in the Morris navigation task (DiMattia \& Kesner, 1988b) and the cheeseboard place learning task (Kesner, Farnsworth, \& DiMattia, 1989), rats with lesions restricted to the parietal area (as defined by Kolb \& Walkey, 1987), were at worst mildly impaired in the navigation task. They failed to swim directly toward the target and displayed inaccurate trajectories, but they were nevertheless able to seek out the platform at the correct 
location (Kolb, Holmes, \& Whishaw, 1987; Kolb, Sutherland, \& Whishaw, 1983; Kolb \& Walkey, 1987; Save \& Moghaddam, 1996; Whishaw, 1987). In addition, posttraining damage impaired place learning only transiently, although rats again displayed poor trajectories (Save \& Moghaddam, 1996). When trained in a spatial task that relies on a go/no-go procedure, rats with APC lesions were transiently impaired in memory for allocentric distance. In contrast, rats with hippocampal lesions displayed a large and permanent impairment (Long \& Kesner, 1996).

APC-lesioned rats were also tested in the Maier threetable task (Maier, 1932), which has in common with the water maze tasks the requirement that rats have to use the relational properties of distal environmental cues. However, the most essential aspect of this task is that spatial learning occurs in the course of an initial exploration phase during which it is assumed that the rats build up a spatial representation (Ellen, Soteres, \& Wages, 1984). Rats with lesions of the APC were initially impaired but progressively improved their performance across trials and had reached the controls' level by the end of the experiment (Thinus-Blanc, Save, Poucet, \& Foreman, 1996). Such improvement was correlated with an increase in the number of tables explored during the initial exploration phase, suggesting that the rats could compensate for deficits due to APC lesions.

As suggested by several authors, exploratory activity is crucial for the building up of spatial maps (O'Keefe \& Nadel, 1978; Poucet, Chapuis, Durup, \& Thinus-Blanc, 1986; Thinus-Blanc et al., 1987). One purpose of exploration is to provide the animal with spatial invariants, therefore allowing it to recognize and identify where it is in space (Poucet, 1993). The ability of APC-lesioned rats to process allocentric information during exploration has been investigated in several studies (Save, Buhot, Foreman, \& Thinus-Blanc, 1992; Save, Poucet, Foreman, \& Buhot, 1992). Usually, the animals were allowed to explore during successive sessions a circular arena containing several objects. Habituation of exploratory activity and reaction to a modification of the object-set configuration were assessed. In addition, the spatial change was followed by a nonspatial change involving the substitution of a familiar object by a novel one. Rats with dorsal hippocampal or APC lesions were impaired at detecting the spatial change but not at detecting the nonspatial change (Save, Poucet, et al., 1992). In this respect, the effects of hippocampal and APC lesions could not be dissociated, suggesting that the two structures are critically important for the identification of the spatial configuration of proximal intramaze objects. Nevertheless, because allocentric construction results from an egocentric process of information collection, it is difficult to determine which coding system is affected by hippocampal or parietal lesions.

Most studies have tested the effects of lesions of the hippocampus and APC in spatial tasks, but they do not actually provide any direct evidence for an interaction between the two structures. Some support to this interaction has been recently provided by a study testing the effects of hippocampal and parietal lesions in two inbred strains of mice, DBA/2 (DBA) and C57BL/6 (C57). These two strains perform differently in spatial tasks, with C57 mice displaying better learning than DBA mice (AmmassariTeule \& Caprioli, 1985; Crusio, Schwegler, \& Lipp, 1987; Upchurch \& Wehner, 1989). DBA mice exhibit a number of hippocampal neurobiological alterations relative to C57 mice. In particular, DBA mice are characterized by a modest mossy fiber projection, which has been shown to be correlated with poor spatial performance (Schwegler \& Crusio, 1995). They also display a lower density of neurons in the CAl region (Wimer et al., 1976) and a lower activity of protein kinase C (Wehner, Sleight, \& Upchurch, 1990) than C57 mice. This has led several authors to consider DBA mice as a genetic model of hippocampal dysfunction (Ammassari-Teule, Tozzi, Rossi-Arnaud, Save, \& Thinus-Blanc, 1995; Douglas, 1975; Paylor, Baskall, \& Wehner, 1993). When confronted with a novel configuration of objects, C57 mice were able to discriminate the spatial change. Such reactivity was abolished by either hippocampal or parietal lesions (Thinus-Blanc, Save, Rossi-Arnaud, Tozzi, \& Ammassari-Teule, 1996). In contrast, nonlesioned DBA mice failed to react to the spatial change. Hippocampal lesion in DBA mice induced a nonspecific decrease in interest toward both categories of objects in the response-to-change phase, whereas, notably, APC lesions did not induce any behavioral change. Furthermore, the differential effects of hippocampal and parietal lesions in DBA mice (with a presumably dysfunctioning hippocampus) raise the possibility that the contribution of the APC to spatial processing depends on the degree of functionality of the hippocampus.

\section{Effects of Lesions on Egocentric Coding}

In spatial tasks requiring egocentric processing of space, the behavioral consequences of APC injuries are diverse. This may be explained by the fact that the term egocentric task includes very different learning situations in terms of processing and attentional requirements. Strikingly, in most studies, APC-lesioned animals have displayed some impairment in the adjustment of their trajectories when navigating toward a goal. Foreman, Save, Thinus-Blanc, and Buhot (1992) found that the trajectories of rats turning and running between familiar visible targets at opposite ends of an arena were less accurate in APC-lesioned rats than in controls. In a water maze task in which the platform was visible, APC-lesioned rats were slightly impaired in correcting their heading angle over trials and differed from control rats. Nevertheless, in a more difficult task in which the location of the hidden platform was marked by a spatially discontiguous visual cue attached to the pool wall, the rats were markedly unable to swim directly toward the target (Kolb \& Walkey, 1987). Although such inaccuracy could have been due to the inability to use a stable visual frame, a similar deficit was also observed when the animals had to swim in total darkness toward a platform always located in the same position relative to the starting place (Save \& Moghaddam, 
1996). This suggests that the accuracy is related to the processing of movement-related information. A recent argument in support of this hypothesis comes from a study of response learning in a "Greek cross" shaped water maze in which performance was also disrupted by APC lesions (McDaniel et al., 1995). Interestingly, the inaccuracy of the trajectories following parietal damage was similar to that seen in tasks requiring both egocentric (Save \& Moghaddam, 1996) and allocentric (Kolb \& Walkey, 1987) tasks. This observation provides indirect evidence that part of the allocentric impairment can be explained by a deficit in egocentric coding.

In contrast, deficits have not been found when APClesioned rats were trained to respond to an egocentrically defined goal location in the eight-arm maze (Kesner et al., 1989; King \& Corwin, 1992). However, if the deficit following APC damage results in the inability to initiate accurate trajectories, this would be much less likely to be revealed in the eight-arm maze because the trajectories are more constrained by the structure of the apparatus.

In summary, although the behavioral consequences of lesions have not always been homogenous from one study to another, APC-lesioned rats have displayed behavioral impairments in both egocentric tasks and allocentric tasks. The heterogeneity of the results may be explained by the fact that in spite of the anatomical studies mentioned earlier, there remains some inconsistency in the location and the size of APC lesions across studies, as, for example, in the Kolb and Walkey (1987), and DiMattia and Kesner (1988b) studies. The area studied by Kolb and Walkey was relatively small and posterior, whereas the area lesioned by DiMattia and Kesner was much larger and more anterior. We have shown that different anterior-posterior lesion placements induce different behavioral effects (Save, Poucet, et al., 1992). Similarly, the lack of effects of APC lesions in Kesner et al.'s egocentric task might be related to their anterior placement. Another explanation for interstudy variability lies in the different nature of the behavioral tasks, which require different forms of egocentric orientation. These different forms might be mediated by different brain structures.

\section{Summary of Lesion Studies}

In navigation tasks requiring the use of extramaze distal cues, APC-lesioned rats display mild deficits. They seem able to learn the location of a goal, but they have difficulty in directing their trajectories toward this goal. In contrast, when APC-lesioned rodents are allowed to explore the available landmarks and process proximal spatial information, they are as impaired as hippocampallesioned rats (in exploration). It is interesting to speculate that the degree of involvement of the APC in the processing of spatial information may vary according to the kind of landmarks that are used for place learning and navigation. Indeed, proximal and distal landmarks provide different information for navigation in terms of reliability and accuracy (Biegler \& Morris, 1996). Due to movement parallax, when the animal is moving around, nearby stim- uli appear to be moving faster than distant stimuli, and the animal is more sensitive to small changes of direction in nearby than in distant stimuli (Thinus-Blanc, 1996, pp. 134-147). Thus, integrating near information and updating one's trajectories by reference to proximal landmarks may be more difficult than by reference to distal (more distant) landmarks. The APC seems to be more critical for navigation using proximal landmarks than distal ones. In contrast, as suggested by recent electrophysiological work (Cressant, Muller, \& Poucet, 1997), the hippocampus would appear to be more concerned with the processing of distal cues than of proximal cues.

\section{ELECTROPHYSIOLOGICAL RECORDINGS}

The study of the role of the hippocampus in spatial processing has greatly benefited from single-cell recordings in the freely moving rat. O'Keefe and Dostrovsky (1971) initiated this field of research when they discovered, in the $\mathrm{CA} 1$ and $\mathrm{CA} 3$ regions of the hippocampus, pyramidal cells ("place cells") that fire intensely when the rat is located in a given region of its environment and are virtually silent when it is outside this region (the "place field"). Since then, their functional properties have been extensively investigated (see Muller, 1996, for a review). The location-specific firing of place cells has been shown to be controlled by visual and nonvisual cues (Muller \& Kubie, 1987; Quirk, Muller, \& Kubie, 1990). When it is possible to record simultaneously from many cells, it can be seen that all parts of a given environment are entirely mapped by a set of place fields of various sizes that are more or less overlapping (Eichenbaum, Wiener, Shapiro, \& Cohen, 1989; Wilson \& McNaughton, 1994). The functional characteristics of place cells constitute compelling support for the cognitive mapping theory, and the hippocampus is considered to be the neural structure wherein allocentric representations of space are constructed and/or implemented (O'Keefe \& Nadel, 1978).

Studies dealing with unit recordings in the APC, by contrast, are relatively few, but the results nevertheless give some hints as to the function of the APC. McNaughton, Leonard, and Chen (1989) recorded parietal cells from a region corresponding to area 7 while the rats were performing a radial maze task. They found cells that were active for specific combinations of movement and views of the environment. Movement correlates were defined as right turns, left turns, and forward motion, and visual correlates as headings toward different parts of the environment. In a study by McNaughton et al. (1994), cortical recordings revealed a more complicated picture. The activity of most recorded cells was found to be correlated with basic modes of locomotion. Nevertheless, in other cells, as indicated previously, movement correlates interacted with the spatial features of the environment. McNaughton et al. (1994) concluded that the APC contains an egocentric representation of the states of motion of the animal. Moreover, the existence of different degrees of correlation among cell activity, movements, and 
spatial features suggests that the APC cells could perform intermediate processes ranging from the "simple" integration of self-motion information to the association between movement and visuospatial information. Head direction cells have also been recorded in the APC (Chen, Lin, Green, Barnes, \& McNaughton, 1994). This population of cells, initially recorded in the postsubiculum of rats (Ranck, 1984; Taube, Muller, \& Ranck, 1990a), has been also found in the anterior and lateral dorsal thalamus nuclei (Mizumori \& Williams, 1993; Taube, 1995). They are strongly active only when the rat's head is oriented in a given direction relative to the environment, irrespective of its location. Therefore, head direction cells show complementary properties to those of place cells. Each cell is characterized by a specific "preferred" direction, defined as a relatively narrow range of angles in the horizontal plane (Taube et al., 1990a, 1990b). In the APC, head direction cells constitute only $3 \%$ of the total, a very small proportion compared with the postsubicu$\operatorname{lum}(26 \%)$ and anterior thalamic nuclei $(60 \%)$. This may suggest that the APC is at the start of a processing route that proceeds and expands in other parts of the brain. Most interestingly, head direction activity in the APC has been found to be modulated by visual and vestibular inputs (Chen, Lin, Barnes, \& McNaughton, 1994). Such findings support the hypothesis that the APC integrates and processes both visual and movement-related information. Nevertheless, the existence of cells with similar firing properties in different regions of the brain suggests that the computation of head direction may require their integration via the involvement of a higher level of integration and processing.

\section{APC FUNCTION: MULTISENSORY ASSOCIATION AND INTERFACING BETWEEN EGOCENTRIC AND ALLOCENTRIC CODING}

Behavioral and lesion studies suggest that hippocampallesioned rats are impaired in tasks requiring allocentric spatial coding whereas APC-lesioned rats are impaired in tasks requiring egocentric and/or allocentric spatial coding. In addition, anatomical and electrophysiological data suggest that the APC could be involved in the processing of visuospatial and movement-related information. Might this constitute the fundamental function of the parietal area in spatial processing and explain the various behavioral deficits observed in navigation tasks? Several studies have focused on the visual component of APC function. It has been shown that APC lesions disrupt complex visual pattern discrimination and learning (McDaniel \& Wall, 1988; McDaniel, Wildman, \& Spears, 1979), but not simple pattern discrimination and black-white reversal learning (Boyd \& Thomas, 1977; Kolb, Buhrman, \& McDonald, 1989; McDaniel \& Thomas, 1978; McDaniel et al., 1979). It would therefore be simple to conclude that the APC is involved in the processing of complex visuospatial information. However, nothing is known about what kind of visuospatial information is actually processed by the APC. Is it related to the relative position of landmarks in space (local views; see McNaughton et al., 1989; Poucet, 1993)? Or might it be related to visual motion-generated input, such as systematic changes in object geometry that occur contingent on movement (Redish \& Touretzky, 1997)?

The movement-related component has been tackled in a recent study by Save and Moghaddam (1996) in which rats had to learn to navigate in total darkness toward a platform in the water maze. The platform was always located at the same position relative to the starting place, so the animals had to rely only on the information provided by their swimming, including vestibular, somatosensory, and proprioceptive information (kinesthetic information) to learn the task. Acquisition was disrupted in APClesioned rats, suggesting that the APC plays a role in the integration of kinesthetic information. Finally, in spatial tasks designed to require the formation of associations between visuospatial information and locomotor response, APC-lesioned rats were found to be impaired (Davis \& McDaniel, 1993).

Thus, from all these data, the idea strongly emerges that the APC integrates and associates visuospatial and movement-related information (see McNaughton et al., 1989 , for a previous statement of this hypothesis). Such information coming from various sensory and kinesthetic receptors is perceived relative to the body axis, direction of walking, and so forth. It is necessarily organized along the body referent and coded in egocentric frames of reference. The multiplication of egocentric views of the environment associated with the movements that are needed to go from one viewpoint to another eventually leads to the extraction of spatial invariants and to the formation of allocentric spatial representations. The electrophysiological and behavioral data reviewed in this paper support the idea that the APC is involved in the progressive integration of different egocentric frames of reference and, in particular, in the association between visuospatial and movement-related information. The fact that APC lesion-induced deficits were exacerbated when the animals had to process nearby information is an additional argument in favor of this hypothesis since this association is particularly important in such processing. Thus, according to our view, the APC appears to operate at the interface between the egocentric and the allocentric coding of space. This may explain why bilateral APC lesions usually induce impairments in both egocentric and allocentric tasks.

The function of an interface between the egocentric and allocentric formats of spatial coding would be to facilitate the integration and transformation of perceptual formats into representational formats. This function is also important for the transformation of representational formats into formats compatible with action. Indeed, adequate motor outputs have to be specified in terms of going forward, turning left or right, and so on, with respect to the current position of the body. So far, it is not clear 
whether the APC is involved in the perceptual side, in the action side, or in both sides of the egocentric-allocentric interface. One of the arguments in favor of a function at the perceptual side is provided by anatomical data showing that the APC receives projections from the visual and somatosensory cortices (Kolb \& Walkey, 1987). However, the APC may also play a role at the action side, as is suggested by the presence of bilateral projections with the frontal cortex, which is involved in the planning of action (Granon \& Poucet, 1995).

\section{THE FUNCTIONAL INTERACTION BETWEEN THE APC AND THE HIPPOCAMPUS}

Behavioral and electrophysiological data suggest that the APC and the hippocampus make different, though complementary, contributions to the processing of space. It is now useful to envision how these two structures might interact. Despite the long-standing study of hippocampal function, interest in this issue is relatively recent. It is nevertheless crucial to the understanding of the functional interaction between different brain structures. As has been underlined previously (McNaughton et al., 1989), when one considers the functional relationships between the hippocampus and the APC, a crucial point is that there are no direct connections between the two structures. Consequently, any "minimal" hippocampo-parietal interaction requires the involvement of other structures such as, for instance, the cingulate and the entorhinal cortices. This fact might be taken as reason for questioning the importance of the interaction altogether. However, that these two structures are not closely related in anatomical terms is not, in fact, critical to the interaction hypothesis. Electrophysiological data show that spatial processing is distributed over a large number of brain structures that are functionally related (Knierim, Kudrimoti, \& McNaughton, 1995) and constitute the elements of a general navigational system (Muller, 1996).

The APC appears to deal with the association of visuospatial and idiothetic inputs. We assume that such associations would result in intermediate representations of the environment in which the importance of egocentric coding would decrease as the importance of allocentric coding increases. As proposed by Poucet (1993), the integration of visual and movement information ultimately yields the formation of a place representation. A place is therefore identified as being the same irrespective of the direction from which it is approached, and regardless of changes of appearance that are associated with different viewpoints. One hypothesis is that the APC contributes to the formation of place representations by providing a preprocessing of local views and movements. The place representations would be completed and implemented in the hippocampus. Indeed, place cell activity appears to be the neural correlate of place representations. This hypothesis contrasts with recent models in which the processing of local views is attributed to the hippocampus
(McNaughton et al., 1989; Redish \& Touretzky, 1997). Another hypothesis is that the APC initiates the acquisition of a memory of the locomotor connectivity between specific local views (McNaughton, 1987). The multiplication of these associations would then contribute to the extraction of spatial invariants (Poucet \& Benhamou, 1997) and may prefigure the allocentric organization of the environment at hippocampal level.

However, these views of the hippocampo-parietal interaction are simplistic. The role of these two structures cannot be isolated from the increasing number of areas whose activity has been shown to be correlated with some spatial aspect of the world. This neural distribution of the processing of spatial information provides an explanation for the fact that, in most behavioral tasks, APC-lesioned rats have been only mildly impaired and have sometimes recovered. In a recent paper, Redish and Touretzky (1997) proposed a model of a general navigational system that takes into account a large neural network including extrahippocampal and intrahippocampal functional networks.

Nevertheless, any model of the functional interaction between the APC and the hippocampus has to take into account that the information flow is bilateral and that the hippocampus-and, more broadly, the hippocampal formation - exerts some control via intermediate structures such as the cingulate cortex (Meunier, Jaffard, \& Destrade, 1991) over the functioning of the APC.

\section{GUIDELINES FOR FURTHER RESEARCH ON APC SPATIAL FUNCTION}

Given the small number of data, further work should be pursued to investigate the role of APC in the processing of spatial information. In particular, according to our hypothesis, egocentric coding should be impaired in APClesioned rats. However, since egocentric coding encompasses different spatial subsystems, it seems important to test the effects of APC lesions in a wide variety of egocentric tasks. This would make it possible to determine which sensory component of egocentric coding is sensitive to APC lesions. For instance, it should be fruitful to distinguish between the visual and kinesthetic components, provided that they are well defined in each task. As suggested by some data, the APC would not be involved in all sorts of egocentric behaviors. It would be also important to dissociate in such tasks the effects of APC lesions from other brain structures such as the caudate nucleus, which has been shown to be involved in the coding of egocentric space (Cook \& Kesner, 1988; Packard \& McGaugh, 1996; Potegal, 1969).

Our main hypothesis is that the hippocampus and the APC play complementary roles in the processing of spatial information. Since there is little direct evidence for this complementarity, it would be necessary to dissociate and compare more systematically the performance of APC and hippocampal-lesioned rats in both egocentric and allocentric tasks. Another possible approach would be to record unit activity in either area in combination with 
lesions of the other area. The fact that, for instance, an APC lesion affects the firing properties of hippocampal place cells would demonstrate that these two structures are closely, functionally interrelated. Conversely, a hippocampal lesion would perhaps induce some modification in the activity of parietal cells such as the head direction cells (provided, of course, that the latter cells could be reliably identified).

It is also possible that knowledge of the role of the APC in rodents may shed light on some aspects of posterior parietal functioning in primates. Indeed, a number of studies have shown that unilateral or bilateral APC lesions induce an attentional impairment (DiMattia \& Kesner, 1988a) and attentional visual neglect (Foreman et al., 1992). Interestingly, hemineglect is a major symptom in patients suffering from unilateral parietal damage (Jeannerod, 1985). Note that the deficit in both rodents and primates can also be described as a disturbance in the processing of egocentric space. Thus, one important issue is to understand how the processing of spatial information is modulated by APC-specific attentional processes.

Finally, a major line of research has focused on the respective roles of the cortex and hippocampus in the formation and storage of the mnesic trace. The hypothesis is that the hippocampus is involved in acquisition and shortterm storage, whereas cortical areas such as the APC are involved in long-term storage of the mnesic trace (McClelland, McNaughton, \& O'Reilly, 1995). Within this theoretical frame, some recent studies have attempted to show retrograde amnesia in the rat following lesion of the APC (Cho, Kesner, \& Brodale, 1995).

Overall, there is strong evidence that the APC plays an important role in the processing of spatial information. Its precise function, in particular with respect to other brain structures such as the hippocampus, remains unclear. Our hypothesis provides predictions regarding the respective roles of the APC and the hippocampus as well as regarding their relationships, which deserve to be tested and approached with different hypotheses. The most difficult work will then be to integrate and to reconcile all the facets of the parietal function in rodents.

\section{REFERENCES}

Ammassari-Teule, M., \& Caprioli, A. (1985). Spatial learning and memory, maze running strategies and cholinergic mechanisms in two inbred strains of mice. Behavioural Brain Research, 17, 9-16.

Ammassari-Teule, M., Tozzi, A., Rossi-Arnaud, C., Save, E., \& Thinus-Blanc, C. (1995). Reactions to spatial and nonspatial change in two inbred strains of mice: Further evidence supporting the hippocampal dysfunction hypothesis in the DBA/2 strain. Psychobiology, 23, 284-289.

Benhamou, S., Bovet, P., \& Poucet, B. (1995). A model for place navigation in mammals. Journal of Theoretical Biology, 173, 163-178.

BIEGLER, R., \& MoRRIS, R. G. M. (1996). Landmark stability: Studies exploring whether the perceived stability of the environment influences spatial representation. Journal of Experimental Biology, 199, 187-193.

Boyd, M. G., \& Thomas, R. K. (1977). Posterior association cortex lesions in rats: Mazes, pattern discrimination, and reversal learning. Physiological Psychology, 4, 455-461.

Chen, L. L., Lin, L-H., Barnes, C. A., \& McNaughton, B. L. (1994).
Head-direction cells in the rat posterior cortex: II. Contribution of visual and ideothetic information to the directional firing. Experimental Brain Research, 101, 24-34.

Chen, L. L., Lin, L-H., Green, E. J., Barnes, C. A., \& McNaughton, B. L. (1994). Head-direction cells in the rat posterior cortex: I. Anatomical distribution and behavioral modulation. Experimental Brain Research, 101, 8-23.

Cho, Y. H, Kesner, R. P., \& Brodale, S. (1995). Retrograde and anterograde amnesia for spatial discrimination in rats: Role of hippocampus, entorhinal cortex, and parietal cortex. Psychobiology, 23, 185-194.

COOK, D., \& Kesner, R. P. (1988). Caudate nucleus and memory for egocentric localization. Behavioral \& Neural Biology, 49, 332-343.

Cressant, A., Muller, R. U., \& Poucet, B. (1997). Failure of centrally placed objects to control the firing fields of hippocampal place cells. Journal of Neuroscience, 17, 2531-2542.

Crusio, W. E., Schwegler, H., \& LiPP, H. P. (1987). Radial maze performance and structural variation of the hippocampus in mice: A correlation with mossy fiber distribution. Brain Research, 425, 182-185.

Davey, M. J., Rose, F. D., Dell, P. A., \& Love, S. (1988). Simultaneous extinction following hemidecortication and unilateral lesions of parietal cortex in the rat. Medical Science Research, 16, 1043-1044.

Davis, B. K., \& McDaniel, W. F. (1993). Visual memory and visual spatial functions in the rat following parietal and temporal cortex injuries. Physiology \& Behaviour, 53, 145-151.

DiMatTia, B. V., \& KeSnER, R. P. (1988a). Role of the posterior parietal association cortex in the processing of spatial event information. Behavioral Neuroscience, 102, 397-403.

DiMATtia, B. V., \& KESNER, R. P. (1988b). Spatial cognitive maps: Differential role of parietal cortex and hippocampal formation. Behavioral Neuroscience, 102, 471-480.

Douglas, R. J. (1975). The development of the hippocampal function: Implications for theory and therapy. In R. J. Douglas \& K. H. Pribram (Eds.), The hippocampus (Vol. 2, pp. 309-326). New York: Academic Press.

Eichenbaum, H. B., Stewart, C., \& Morris, R. G. M. (1990). Hippocampal representation in place learning. Journal of Neuroscience, 10, 3531-3542.

Eichenbaum, H. B., Wiener, S. I., Shapiro, M. L., \& Cohen, N. J. (1989). The organization of spatial coding in the hippocampus: A study of neural ensemble activity. Journal of Neuroscience, 9, 2764-2775.

Ellen, P., Soteres, B. J., \& Wages, C. (1984). Problem solving in the rat: Piecemeal acquisition of cognitive maps. Animal Learning \& Behavior, 12, 232-237.

Faugier-Grimaud, S., Frenois, C., \& Stein, D. G. (1978). Effects of posterior parietal lesions on visually guided behavior in monkeys. Neuropsychologia, 16, 151-168.

Foreman, N., Save, E., Thinus-Blanc, C., \& Buhot, M.-C. (1992). Visually guided locomotion, distractibility and the missing stimulus effect in hooded rats with unilateral and bilateral lesions of parietal cortex. Behavioral Neuroscience, 106, 529-538.

GRANON, S., \& PoucET, B. (1995). Medial prefrontal lesions in the rat and spatial navigation: Evidence for impaired planning. Behavioral Neuroscience, 109, 474-484.

HYVÄRINEN, J. (1982). Posterior parietal lobe of the primate brain. Physiological Review, 62, 1060-1129.

JEANNEROD, M. (1985). The posterior parietal area as a spatial generator. In D. J. Ingle, M. Jeannerod, \& D. N. Lee (Eds.), Brain mechanisms and spatial vision (pp. 279-298). Dordrecht: Martinus Nijhoff.

Kesner, R. P., Bolland, B. L., \& DaKIS, M. (1993). Memory for spatial locations, motor response, and objects: Triple dissociation among the hippocampus, caudate nucleus, and extrastriate visual cortex. Experimental Brain Research, 93, 462-470.

Kesner, R. P., Farnsworth, G., \& DiMattia, B. V. (1989). Double dissociation of egocentric and allocentric space following medial prefrontal and parietal cortex lesions in the rat. Behavioral Neuroscience, 103, 956-961.

KING, V. R., \& CoRwIN, J. V. (1992). Spatial deficits and hemispheric asymmetries in the rat following unilateral and bilateral lesions of posterior parietal or medial agranular cortex. Behavioural Brain Research, 50, 53-68. 
Knierim, J. J., Kudrimoti, H. S., \& McNaughton, B. L. (1995). Place cells, head direction cells, and the learning of landmark stability. Journal of Neuroscience, 15, 1648-1659.

KoLB, B. (1990). Posterior parietal and temporal association cortex. In B. Kolb \& R.C. Tees (Eds.), The cerebral cortex of the rat (pp. 459-471) Cambridge, MA: MIT Press.

Kolb, B., Buhrman, K., \& MCDonald, R. (1989). Dissociation of prefrontal, posterior parietal, and temporal cortical regions to spatial navigation and recognition memory in the rat. Society for Neuroscience Abstracts, 15, 607 .

KolB, B., Holmes, C., \& WhishaW, I. Q. (1987). Recovery from early cortical lesions in rats: III. Neonatal removal of posterior parietal cortex has greater behavioral and anatomical effects than similar removals in adulthood. Behavioural Brain Research, 26, 119-137.

Kolb, B., Sutherland, R. J., \& WhishaW, I. Q. (1983). A comparison of the contributions of frontal and parietal association cortex to spatial localization in rats. Behavioral Neuroscience, 97, 13-27.

KOLB, B., \& WALKEY, J. (1987). Behavioural and anatomical studies of the posterior parietal cortex in the rat. Behavioural Brain Research, $23,127-145$

KolB, B., \& WhISHAW, I. Q. (1983). Dissociation of the contributions of the prefrontal, motor and parietal cortex to the control of movement in the rat: An experimental review. Canadian Journal of Psychology, 37, 211-232

KRIEG, W. J. S. (1946). Connections of the cerebral cortex: 1. The albino rat: A. Topography of the cortical areas. Journal of Comparative Neurology, 84, 221-275.

LASHLEY, K. S. (1929). Brain mechanisms and intelligence. Chicago: University of Chicago Press.

LASHLEY, K. S. (1941). Thalamo-cortical connections of the rat's brain. Journal of Comparative Neurology, 75, 67-121.

LONG, J. F., \& KESNER, R. P. (1996). The effects of dorsal versus ventral hippocampal, total hippocampal, and parietal cortex lesions on memory for allocentric distance in rats. Behavioral Neuroscience, 110, 1-11.

LYNCH, J. C. (1980). The functional organization of the posterior parietal cortex. Behavioral \& Brain Sciences, 3, 485-499.

MAIER, N. R. F. (1932). A study of orientation in the rat. Journal of Comparative Psychology, 14, 387-399.

McClelland, J. L., McNaughton, B. L., \& O'Reilly, R. C. (1995). Why there are complementary learning systems in the hippocampus and neocortex: Insights from the successes and failures of connectionist models of learning and memory. Psychological Review, 102, 419-457.

McDaniel, W. F., MCDaniel, S. E., \& Thomas, R. K. (1978). Thalamocortical projections of the temporal and parietal association cortices in the rat. Neuroscience Letters, 7, 121-125.

McDaniel, W. F., \& Thomas, R. K. (1978). Temporal and parietal association cortex lesions and spatial and black-white reversal learning in the rat. Physiological Psychology, 7, 300-305.

McDaniel, W. F., Via, J. D., Smith, J. S., Wells, D. L., Fu, J. J., BISHOP, J. F., BOYD, P. A., \& LEDESMA, H. M. (1995). Unilateral injury of posterior parietal cortex and spatial learning in hooded rats. Behavioural Brain Research, 70, 165-179.

MCDANIEL, W. F., \& WALL, T. T. (1988). Visuospatial functions in the rat following injuries to striate, peristriate, and parietal neocortical sites. Psychobiology, 16, 251-260.

MCDaniel, W. F., WILdMan, L. D., \& Spears, R. H. (1979). Posterior association cortex and visual pattern discrimination in the rat. Physiological Psychology, 7, 241-244.

McDonald, R. J., \& White, N. M. (1994). Parallel information processing in the water maze: Evidence for independent memory systems involving dorsal striatum and hippocampus. Behavioral \& Neural Biology, 61, 260-270.

MCNAughton, B. L. (1987). Neural association of movement and space: Preliminary steps toward a non-cartographic theory of spatial representation and learning. Neumoscience Letters, 29 (Suppl.), S143-S144.

McNaughton, B. L., Leonard, B., \& Chen, L. [L.] (1989). Corticalhippocampal interactions and cognitive mapping: $A$ hypothesis based on reintegration of the parietal and inferotemporal pathways for visual processing. Psychobiology, 17, 236-246.

MCNaughton, B. L., Mizumori, S. J. Y., Barnes, C. A., Leonard, B. J.,
MarQuis, M., \& GreEN, E. J. (1994). Cortical representation of motion during unrestrained spatial navigation in the rat. Cerebral Cortex, 4, 27-39.

Meunier, M., Jaffard, R., \& Destrade, C. (1991). Differential involvement of anterior and posterior cingulate cortices in spatial discriminative learning in a T-maze in mice. Behavioural Brain Research, 44, 133-143.

MEYER, D. R. (1984). The cerebral cortex: Its role in memory storage and remembering. Physiological Psychology, 12, 81-88.

Mizumori, S. J. Y., \& Williams, J. D. (1993). Directionally selective mnemonic properties of neurons in the lateral dorsal nucleus of the thalamus of rats. Journal of Neuroscience, 13, 4015-4028.

Morris, R. G. M., Garrud, P., Rawlins, J. N. P., \& O'KeEFE, J. (1982). Place navigation impaired in rats with hippocampal lesions. Nature, 297, 681-683.

MULLER, R. U. (1996). A quarter of a century of place cells. Neuron, 17, 813-822.

MULLER, R. U., \& KuBIE, J. L. (1987). The effects of changes in the environment on the spatial firing of hippocampal complex-spike cells. Journal of Neuroscience, 7, 1951-1968.

NADEL, L. (1991). Varieties of spatial cognition: Psychobiological considerations. In A. Diamond (Ed.), The development and neural bases of higher cognitive functions (Annals of the New York Academy of Sciences, Vol. 608, pp. 613-626). New York: New York Academy of Sciences.

O'KeEFE, J., \& Dostrovsky, J. (1971). The hippocampus as a spatial map: Preliminary evidence from unit activity in the freely moving rat. Brain Research, 34, 171-175.

O'KEEFE, J., \& NADEL, L. (1978). The hippocampus as a cognitive map. Oxford: Oxford University Press, Clarendon Press.

PaCKard, M. G., \& McGaugh, J. L. (1992). Double dissociation of fornix and caudate nucleus lesions on acquisition of two water maze tasks: Further evidence for multiple memory systems. Behavioral Neuroscience, 106, 439-446.

PACKARD, M. G., \& MCGAUGH, J. L. (1996). Inactivation of hippocampus or caudate nucleus with lidocaine differentially affects expression of place and response learning. Neurobiology of Learning \& Memory, 65, 65-72.

Paylor, R., Baskall, L., \& Wehner, J. M. (1993). Behavioral dissociations between $\mathrm{C} 57 \mathrm{BL} / 6$ and $\mathrm{DBA} / 2$ mice on learning and memory tasks: A hippocampal-dysfunction hypothesis. Psychobiology, 21, 11-26.

Potegal, M. (1969). The role of the caudate nucleus in spatial orientation of rats. Journal of Comparative \& Physiological Psychology, 69, 756-764.

POuCET, B. (1993). Spatial cognitive maps in animals: New hypotheses on their structure and neural mechanisms. Psychological Review, 100, 163-182.

Poucet, B., \& Benhamou, S. (1997). The neuropsychology of spatial cognition in the rat. Critical Reviews in Neurobiology, 11, 101-120.

Poucet, B., Chapuis, N., Durup, M., \& Thinus-Blanc, C. (1986). A study of exploratory behavior as an index of spatial knowledge in hamsters. Animal Learning \& Behavior, 14, 93-100.

Quirk, G. J., Muller, R. U., \& KuBIE, J. L. (1990). The firing of hippocampal place cells in the dark depends on the rat's recent experience Journal of Neuroscience, 10, 2008-2017.

RANCK, J. B., JR. (1984). Head-direction cells in the deep layers of dorsal presubiculum in freely moving rats. Society for Neuroscience $A b$ stracts, 10, 599 .

Redish, A. D., \& TouretzKy, D. S. (1997). Cognitive maps beyond the hippocampus. Hippocampus, 7, 15-35

Reep, R. L., Chandler, H. C., King, V., \& Corwin, J. V. (1994). Rat posterior parietal cortex: Pattern of connectivity. Experimental Brain Research, 100, 67-84.

Save, E., Buhot, M.-C., Foreman, N., \& Thinus-Blanc, C. (1992). Exploratory activity and response to a spatial change in rats with hippocampal or posterior parietal cortical lesions. Behavioural Brain Research, 47, 113-127.

Save, E., \& Moghaddam, M. (1996). Effects of lesions of the associative parietal cortex on the acquisition and use of spatial memory in 
egocentric and allocentric navigation tasks in the rat. Behavioral Neuroscience, 110, 74-85.

Save, E., Poucet, B., Foreman, N., \& Buhot, M.-C. (1992). Object exploration and reactions to spatial and nonspatial changes in hooded rats following damage to parietal cortex or hippocampal formation. Behavioral Neuroscience, 106, 447-456.

SCHWEGLER, H., \& CRUSIO, W. E. (1995). Correlations between radialmaze learning and structural variations of septum and hippocampus in rodents. Behavioural Brain Research, 67, 29-41.

TAUBE, J. S. (1995). Head direction cells recorded in the anterior thalamic nuclei of freely moving rats. Journal of Neuroscience, 15, 70-86

TaUbe, J. S., Muller, R. U., \& RanCK, J. B. (1990a). Head direction cells recorded from the postsubiculum in freely moving rats: I. Description and quantitative analysis. Journal of Neuroscience, 10, 420-435.

Taube, J. S., Muller, R. U., \& RaNCK, J. B. (1990b). Head direction cells recorded from the postsubiculum of freely moving rats: II. The effects of environmental manipulations. Journal of Neuroscience, 10 , 436-447.

Thinus-Blanc, C. (1996). Animal spatial cognition: Behavioral and neural approaches. Singapore: World Scientific Publishing.

Thinus-Blanc, C., Bouzouba, L., Chaix, K., Chapuis, N., Durup, M., \& PouCET, B. (1987). A study of spatial parameters encoded during exploration in hamsters. Journal of Experimental Psychology: Animal Behavior Processes, 13, 418-427.

Thinus-Blanc, C., Save, E., Buhot, M. C., \& Poucet, B. (1991). The hippocampus, exploratory activity, and spatial memory. In J. Paillard (Ed.), Brain and space (pp. 168-182). Oxford: Oxford University Press.

Thinus-Blanc, C., Save, E., Poucet, B., \& Foreman, N. (1996). Effects of parietal cortex lesions in spatial problem solving in the rat. Behavioural Brain Research, 81, 115-121.

Thinus-Blanc, C., Save, E., Rossi-Arnaud, C., Tozzi, A., \&
Ammassari-Teule, M. (1996). The differences shown by C57BL/6 and DBA/2 inbred mice in detecting spatial novelty are subserved by a different hippocampal and parietal cortex interplay. Behavioural Brain Research, 80, 33-40.

Thomas, R. K., \& WeIR, V. K. (1975). The effects of lesions in the frontal or posterior association cortex of rats on Maze III. Physiological Psychology, 3, 210-214.

THOMPSON, R. (1979). Hippocampal and cortical function in a maze devoid of left and right turns. Physiology \& Behavior, 23, 601-603.

UPCHURCH, M., \& WEHNER, J. (1989). Inheritance of spatial learning ability in inbred mice: a classical genetic analysis. Behavioral Neuroscience, 103, 1251-1258.

WehNer, J. M., SLEIGHT, S., \& UPChURCh, M. (1990). Hippocampal protein kinase $\mathrm{C}$ activity is reduced in poor spatial learners. Brain Research, 523, 181-187.

WhishaW, I. Q. (1987). Hippocampal granule cell and $\mathrm{CA}_{3-4}$ lesions impair formation of a place learning-set in the rat and induce reflex epilepsy. Behavioural Brain Research, 27, 59-72.

Whishaw, I. Q., \& JARRARD, L. E. (1996). Evidence for extrahippocampal involvement in place learning and hippocampal involvement in path integration. Hippocampus, 6, 513-524.

Wilson, M., \& MCNaughton, B. L. (1994). Dynamics of the hippocampal ensemble code for space. Science, 261, 1055-1058.

Wimer, R. E., Wimer, C. C., Vaughn, J. E., Barber, R. P., Balvanz, B. A., \& Chernow, C. R. (1976). The genetic organization of neuron number, Ammon's horns of house mouse. Brain Research, 118, 219-243.

(Manuscript received October 1, 1997; revision accepted for publication February 3, 1998.) 